\title{
Boston University
}

From the SelectedWorks of Laura Hartman

2012

\section{Trust After the Global Financial Meltdown}

P. werhane, DePaul University

laura hartman, DePaul University

d. bevan

k. clark, DePaul University

c. archer, Northwestern University 


\title{
Trust after the Global Financial Meltdown
}

\author{
PATRICIA WERHANE, LAURA HARTMAN, CRINA ARCHER, \\ DAVID BEVAN, AND KIM CLARK
}

\begin{abstract}
Over the last decade, and culminating in the 2008 global financial meltdown, there has been an erosion of trust and a concomitant rise of distrust in domestic companies, multinational enterprises, and political economies.

In response to this attrition, this article presents three arguments. First, we suggest that trust is the "glue" of any viable political economy, and we propose that the stakes of violating public trust are particularly high in light of the asymmetry between trust and distrust. Second, we identify a constellation of key barriers to overcoming distrust that companies face in the current environment: (1) corporate mind-sets that promote a preoccupation with quantification, hierarchical leadership models, and "blind trust" in authority; (2) the anonymity of core stakeholders; (3) the agency of the media as a
\end{abstract}

\footnotetext{
Patricia Werhane is the Wicklander Chair of Business Ethics in the Department of Philosophy and Managing Director of the Institute for Business and Professional Ethics at DePaul University, Chicago, IL. E-mail: pwerhane@depaul.edu. Laura Hartman is the Vincent de Paul Professor of Business Ethics in the Department of Management and Research Director of the Institute for Business and Professional Ethics at DePaul University, Chicago, IL. E-mail: lhartman@depaul.edu. Crina Archer is a PhD Candidate in the Department of Political Science at Northwestern University, Evanston, IL. E-mail: c-archer@northwestern.edu. David Bevan is a Professor of Management at Grenoble Graduate Business School, Grenoble, France. E-mail: david.bevan@grenoble-em.com. Kim Clark is a Lecturer in the College of Computing and Digital Media and Wicklander Fellow at the Institute for Business and Professional Ethics at DePaul University, Chicago, IL. E-mail: kclark17@depaul.edu.
} 
driver of the political economy; and (4) firm-centric models of stakeholder relationships.

Third, we argue that, notwithstanding these challenges, these phenomena are not fatal and can be addressed through a holistic transformation in corporate culture. Such a transformation might include a shift to collaborative leadership models and replacing authority models with responsibility, a "names and faces" approach to stakeholders through cases and stories, more egalitarian communication exchanges with external stakeholders, and a reprioritization of the firm as a vital element among others within a system rather than the central core of a network.

We conclude that the value of trust at the individual, institutional, national, and global levels cannot be overstated. Without a reinvigoration of trust in our political economies, at all levels, the future of an economically vibrant planet is indeed bleak.

\section{INTRODUCTION}



ince the Enron disaster in 2001 and culminating in the 2008 global financial meltdown, we have seen an erosion of trust and a concomitant rise of distrust in domestic companies, in multinational enterprises, and in political economies. In light of this attrition, and despite the continued global expansion of free enterprise, we share the trepidation expressed by the comment of European Commission President Manuel Barroso (2009) at the G20 Global Summit: "[t]his crisis is much more than an economic or financial crisis. It is also a crisis of the way we deal with our societies. It is a crisis about the values that we should respect." Part of this crisis, we argue, is a disintegration of trust in our economic and political institutions.

In this article we will make three arguments. First, we will suggest that trust is the "glue" of any viable political economy, without which, as Hobbes (1651/1996) once wrote, "the life of man [would be] solitary, poor, nasty, brutish, and short." Indeed, it is this "glue" that accounts for the fact that we do not see more 
global corruption and fraud, as it is otherwise so easy to lie, cheat, and steal in free economies. The stakes of violating public trust are particularly high in light of the asymmetry between trust and its contrary relational category, distrust (Hardin 2002; Kramer 1999; La Porte and Metlay 1996; Slovic 1993). Trust relations require a mutual expectation of competence and shared values between the parties, and tend to develop over many interactions. In contrast, arising from expectations of incongruent values, distrustful relations are significantly easier to generate and more difficult to repair.

Second, the mind-sets of our Western political economies often belie the value of trust. We will trace several of these mind-sets, which lead to the downgrading of trust in free enterprise. One of these is the persistent preoccupation with quantification, or totalization, of all market exchanges, including the calculation of trust in monetary terms. Other reasons include the persistence of hierarchical leadership models, the "herd" mentality of many employees, and the age-old problem of obedience to authority so clearly articulated by the Milgram experiments in the 1960s (Milgram 1963, 1969). Still other causes include the anonymity of core stakeholders, for example, employees, customers, and shareholders; the agency of the media as a driver of the political economy; and, in theory, the instrumentally firm-centric model of stakeholder relationships.

Third, we will argue that, notwithstanding these challenges, these phenomena are not fatal and can be addressed through a transformation in corporate culture that might include shifting to collaborative leadership models, replacing authority models with responsibility, giving "names and faces" to stakeholders through cases and stories, forging more egalitarian communication exchanges with external stakeholders, integrating habitpreventing programs into embedded corporate cultures, and reprioritizing the firm as a vital element among others within a system rather than the central core of a network.

We conclude that the value of trust at the individual, institutional, national, and global levels cannot be overstated. Without a reinvigoration of trust in our political economies, at all levels, the future of an economically vibrant planet is indeed bleak. 


\section{THE “GLUE” OF TRUST}

Fukuyama (1995) explains that the term trust "defines a set of relationships between individuals, organizations, or political economies, a commonality on some level of mutual reliance or expectations that one's word and agreements will be honored. The good will of each party is assumed usually without written contracts or legal documents." Trust also involves "the [continued] expectation of the persistence and fulfillment of the existing social order" (p. 5). When one has been in a trust relationship for some time, one becomes confident of future relationships of trust, at least within the context of that relationship. As philosopher George Brenkert (1998) notices, there are shared values underpinning a trust relationship, although they may be particular to that context or relationship. People with different value perspectives often trust each other in certain kinds of circumstances and then not in others. Thus, strong trust relationships entail not merely reciprocity but also a recognition and respect of each party for the other, at least within defined trust circumstances (Ricoeur 2005).

Moreover, "trust is an important lubricant of a social system. It is extremely efficient. It saves a lot of trouble to have a fair degree of reliance upon other people's word..." (Arrow 1974, p. 23). Trust enables social and economic interactions; it undergirds the believability of history. Trust relations-this glue-may also be perceived as more provisional and continuously reconstituted in experience (Bauman 1993) and thus susceptible to interruption and variation from one moment to the next. In other words, trust is the medium that brings human societies together and makes their existence and progress possible. In commerce, trust includes “. . . [t] he probability that one economic actor will make decisions and take actions that will be beneficial or at the least not detrimental to another ..." (Gambetta 1998, p. 227), thus reducing transaction costs. However, when one is wronged, cheated, or unreasonably exploited, trust is diminished or evaporates provisionally until it is consensually restored.

\section{TRUST AND DISTRUST}

In contrast to scholarly approaches that tend to take a symmetrical view of distrust, defining the concept as the absence of those 
characteristics imputed to trust relations (Arrow 1974; Barber 1983), many researchers propose that trust and distrust are more effectively conceptualized as distinct relational categories (Hardin 2002; Lewicki et al. 1998; Luhmann 1979; Sitkin and Roth 1993). Trust is absent where the parties do not presume reciprocal goodwill or shared values. Distrust, in contradistinction, describes a relationship characterized by the assumption that the other party will act opportunistically, or even malevolently, if given the chance (Cho 2006). As Lewicki et al. (1998) assert, "[t]rust and distrust both entail certain expectations, but whereas trust expectations anticipate beneficial conduct from others, distrust expectations anticipate injurious conduct” (p. 444).

Assessments of trustworthiness are made according to both nonmoral and moral criteria. In its nonmoral dimension, trust entails the belief that the trustee is competent in the relevant relationship sphere; normative evaluations of trust presume that certain key values are shared with the trustor (Earle 2009; Poppo and Schepker 2010; Sengün and Wasti 2010; Sitkin and Roth 1993; Uslaner 2010). ${ }^{1}$ Sitkin and Roth (1993) suggest that perceived value incongruence is more likely to lead to distrusting relations because of the perception that the other party does not share one's normative convictions and may therefore act opportunistically in the relationship. By contrast, perceptions of incompetence are more likely to lead to lower levels of trust rather than to the production of active distrust. When we determine that someone is unreliable or incapable of performing the functions required by their role, we may deem them untrustworthy. However, this judgment tends not to lead to the expectation of malevolent or opportunistic behavior associated with distrust. Relationships of trust and distrust are also distinguished by their asymmetrical grounds (Hardin 2002; Kramer 1999; La Porte and Metlay 1996; Slovic 1993). Trust is built over repeated interactions, with each positive interaction generating new opportunities to thicken the "glue" of the trusting relation. Conversely, very few interactions are required to establish distrust (sometimes even just one), and the assumption of the other party's opportunistic intentions closes down further relational opportunities. Thus, it is quite difficult to establish mutual trust where distrusting relations dominate, while it is comparatively easier for a trusting relation to "flip" into one of distrust (Hardin 2002, p. 90). 


\section{CHALLENGES TO TRUST}

The concept of distrust is illustrated by a number of key features in today's market environment. Public trust in some market areas-particularly banking-is not only low but, as the 2010 Edelman Trust Barometer reports, it is actively plummeting, a situation suggesting a growing and pervasive distrust of the financial sector. Despite some indications that recent corporate and government actions have had limited success in increasing public confidence in business over the past year, 70 percent of the informed global public believes that corporations will return to "business as usual" when the financial crisis abates (Edelman 2010 , p. 4). Further, the basis of public trust assessments of corporations has shifted in recent years, with competency factors-such as financial performance and product qualitybecoming less relevant to corporate reputation and value congruence factors-such as honesty and transparency-gaining in significance (p. 6). Increasingly, public evaluations of corporate trustworthiness involve moral scrutiny as well as traditional concerns about reliability and profitability. These sharp declines in public trust, broad perceptions of corporate opportunism, and the rising importance of shared values in stakeholder/firm trust relations compound widespread public distrust of political institutions (Pew Research Center 2010) to produce a high bar for regenerating trust in our political economies.

Worse, this loss of trust and increase of distrust tends to erode all societal relationships. ${ }^{2}$ Indeed, as Adam Smith (1762/1976) once wrote, "Society may subsist, thought not in the most comfortable state, without beneficence, but the prevalence of injustice must utterly destroy it" (II.ii.3.3). How did this malaise develop, and what can be done to repair this critical element of human well-being? As we indicated in the Introduction, there are a myriad of reasons for the loss of trust in free enterprise. We will elaborate on each of these.

According to Kenneth Arrow (1974), the Nobel Prize economist, "trust and similar values are examples of what economists would call 'externalities.' They are goods; they are commodities; they have real practical economic value; they increase efficiency in the system, enable you to produce more goods of more of what ever values you hold in high esteem. But they are not commodities for 
which trade on the open market is technically possible or even meaningful" (p. 23). Important as it is, we cannot put a dollar price on trust. We cannot commodify it in the ways in which we commodify other economic phenomena. In our present political economy, which measures economic value primarily in dollars or Euros, trust, then, becomes devalued. For example, a recent Financial Times article claimed that the market capitalization of the FT 500 companies in May 2010 was $\$ 23,503$ billion (Dullforce 2010). And we tend to value companies in those terms rather than in terms of their ability to generate trust or their interests in corporate social responsibility. Even corporate social responsibility is sometimes measured only in self-interested returns on investment; we still find companies going back to Milton Friedman's (1970) claim that so-called corporate social responsibility should only be undertaken if it is in the interest of the shareholders to do so. Of course, Friedman carefully qualified his conclusion with the provisos that companies do not engage in deception, illegalities, or fraud and that they compete fairly, respect contracts, and satisfy customers (Bird and Waters 1989; Friedman 1970). Yet the fact that Friedman is read as focused on corporate self-interests in stock share returns has resulted in a corporate preoccupation with profitability. Consequently, trust gets a "backseat" in our thinking and is devalued despite its centrality to market exchanges.

The reason for this consequence and other modes of devaluing trust is the persistence of a certain set of mental models or mind-sets that pervade some Western capitalist political economies, particularly in the United States, ${ }^{3}$ one of which we have illustrated with the example of corporate preoccupation with profitability. Related to that mind-set, simply put, is the preoccupation with financial capital as the primary form of measuring value added, even in noncommercial settings. For example, running for public office in the United States is now an expensive proposition, with the cost of winning an election to the House nearly doubling over the past two decades (Ornstein et al. 2008, p. 74). Those potential candidates who are qualified in other respects but cannot garner campaign funds are likely to be excluded from competition. Ordinarily, votes cannot literally be bought, but good public relations (PR) and paid advertising does help to win votes (or lose votes for the opponent). This monetary mind-set obviously 
dominates commerce as well as politics, and markets are sometimes (but not always) incapable of measuring the value-added that companies create in other than monetary terms, even if they are offering critical goods and services. For example, Merck Pharmaceuticals has spent over $\$ 100$ million developing a drug for river blindness, a disease that strikes large populations in developing countries (Bollier et al. 1991). Merck has given away over 744 million doses of Mectizan, the drug that arrests the development of this disease (Merck Pharmaceuticals 2010). Yet this immense value added to humanity is not taken into account as an asset in their financial reporting, nor is it measurably valued by the financial markets. Thus, "soft" values such as trust and integrity, or social contributions such as Mectizan, are excluded from assessments of worth.

A second reason for the devaluation of trust in our political economies is the persistence of hierarchical leadership models. The literature on leadership abounds with leadership-follower models. For example, Gardner and Laskin (1995) defines leaders as "individuals who significantly influence the thoughts, behaviors, and/or feelings of others" (p. 60). Yet in a global economy where transnational enterprises enter multiple markets, this model fails to capture the complex cultural interactions and sensitivities necessary for conducting a viable business in these diverse settings. Moreover, as many studies have shown (Adler 1997; Rosener 1990; Werhane et al. 2007), women and minorities in leadership positions may not necessarily thrive on this model; they often leave hierarchically structured companies to start their own enterprises because they distrust organizations that continue to devalue the contributions of middle managers. This distrust is exacerbated by the fact that, in 2010, despite growing gender and diversity parity in the workforce, over 90 percent of all global corporations are run by men, most of them white (Catalyst 2010).

One of the problems with a hierarchical model is that it can lead to blind trust, which "denies the very possibility of distrust, despite all of the evidence that this or that person is not to be trusted" (Flores and Solomon 1998, p. 215). In a recent article, Stephen Young (2010) argues that part of the reason for this phenomenon is that "organizational imperatives reward loyalty and team-players, those who get along and go along." These imperatives encourage risk-averse behavior, often reduce employ- 
ment anxiety, and give the manager or employee a "sense of security" to be part of the organization. Yet, as we have seen in the recent financial crisis, the costs of encouraging blind trust are high. In the recent subprime mortgage implosion, many mortgage brokers were simply given a quota to fill and told to "sell" mortgages without clear qualification guidelines. Many salespersons did that very well without either questioning the orders or carefully evaluating their mortgage clients. At AIG, where those who questioned their reinsuring behavior were ignored, few people asked critical questions such as what and who they were reinsuring, what was the net value, who were these loan recipients, and what was their net worth-simple questions that were lost in the frantic drive to satisfy present clients and create more business (Lewis 2009). Even more recently, the evidence from the robo-signing scandal suggests that employees regularly signed important mortgage documents with others' names (in one instance, using the name of a woman dead since 1995), apparently without questioning the validity or ethics of these practices (Silver-Greenberg 2010).

This failure to question authority was carefully documented in the 1960s by Stanley Milgram at Yale University in his illustrious study of human obedience to authority. Milgram's experiment was designed to test the hypothesis that a willingness to obey authority can account for behavior that an individual would otherwise avoid and would regard as wrong. Sixty-five percent of the "teachers" in the original study delivered what they understood to be the maximum shock of 450 volts to "learners" who were perfect strangers, because of the teachers' perceptions of and respect for the authority of the experimenter in charge (Milgram 1963). It is important to note that many of the subjects became extremely agitated, distraught, and angry at the experimenter. Yet they continued to follow orders, pressing the 450-volt lever. ${ }^{4}$ Apparently, we often seem willing to go along with what we perceive to be a knowledgeable authority figure, even when we are asked to engage in absurd, dangerous, and unethical practices.

A third reason for the attenuation of trust has to do with anonymity. In large companies with thousands of employees and hundreds of thousands of customers and shareholders, it is impossible for decision makers to represent each of these stakeholder constituents by their individual names and faces. As a 
result, we talk in numbers. For example, by the middle of 2009, 14 million homes in the United States were valued at less than the mortgage debt held on those homes (Cendrowski 2009). When individual mortgages are bundled and described in this manner, they are classified by the value of the bundle, and sometimes, one forgets that each mortgage in that bundle represents home ownership by a household of real people, families, and parents. When banks and hedge funds are trading bundles of mortgages, they are also trading these family futures, but this fact tends to get lost in large-scale enterprises. Similarly, we often forget that stock represents shares owned by individuals and funds, so that profitability matters in this distributive sense as well. The trust that might be fostered in individual relationships is not sought after because it mistakenly appears that one is dealing merely with numbers and capital, not real people. An effectively developed stakeholder theory responds to this anonymity by proposing that stakeholder relationships are reciprocal relationships between the firm and those who most closely affect and are affected by the firm (Freeman 1984/2010). But often, without adding names and faces to these relationships, we risk falling into the trap of explaining reciprocity between collective groups and exchanges without taking into account the individuals that comprise these collectives. ${ }^{5}$

Fourth, distrust in business has been impacted by increasing and generalized skepticism of information sources, as changes in information and communication technologies (ICTs) have impacted contemporary news media. The advent of new technologies at the turn of the century and since, creating a pace to business that is both breathtaking and awe inspiring, has left in its wake not only extraordinary efficiencies but also congruent anxieties about what is known versus what is (perceived as) the vast morass of what is unknown. In addition to the "digital divide" that marginalizes geographic and demographic sectors with limited or no access to new ICTs from the increasingly digitized global economy (Guillén and Suárez 2005; Mossberger et al. 2003), the explosive growth of ICT innovations has spawned "computer anxiety," a term coined to describe "an affective response that reflects apprehension and fear felt by an individual when he or she is using or considering the implications of using computer technology" (Suri et al. 2003, p. 516; also Karavidas et al. 2005; 
Matanda et al. 2004; Wilfong 2006). For example, consider the rise of 24-hour news cycles as opposed to standard reporting, which has contributed to the general reduction in the day-to-day role of trust in the credibility of media information (Rosenberg and Feldman 2008). The intended cultural effect was simply to provide enhanced access to news stories for a broader general public and to provide easier engagement with the many small items that had been neglected by traditional reporting, which would increase the competency of the news media in fulfilling its public function. The unintended consequence, however, has been quite different. As Tony Blair (2007) remarked, in an impassioned speech critiquing the contemporary state of public/media relations: "It used to be thought-and I include myself in this-that help was on the horizon. New forms of communication would provide new outlets to by-pass the increasingly shrill tenor of the traditional media. In fact, the new forms can be even more pernicious, less balanced, more intent on the latest conspiracy theory multiplied by five." Blair's comments suggest that the value commitments of the contemporary news media are perceived by many to be incongruous with the norms of public morality. The addition of countless news web sites and blogs to the media landscape in recent years has amplified the volume and multiplied the number of news outlets streaming information to the public day and night without improving societal trust in news media. In the United States today, 57 percent of the public views the national news media as a negative influence on the direction of the country (Pew Research Center 2010). Among older, informed publics, trust in television news has declined by more than 20 percent since 2008, and information from newspaper articles, Internet search engines, and social networking sites ranks at the bottom of lists of trustworthy sources for information about a company (Edelman 2010).

Clark et al. (2004) studied the effects of this changing media environment on the financial industry. While they found that by the late 1990s, a broad, heterogeneous audience for "financial infotainment" had emerged to replace the narrow audience of financial professionals who previously consumed market reporting, a peculiar lack of financial literacy accompanied this transformation. Despite the proliferation of cable television and, soon thereafter, Internet sources of financial reporting and platforms for online trading, Clark et al. (2004) conclude that "a paradox of 
the new financial literacy is that information is both less valuable in its own right and harder to judge in terms of its integrity. Information is clearly not knowledge" (pp. 296-297). This "paradox" is not primarily the result of the sheer number of information sources, but of the shift in the presentation of financial news toward entertainment models that require continual new stories, seek out and create celebrities, compete to set trends (which therefore change rapidly), use techniques of "theatricality," and are invested in producing emotional responses in the viewing or reading audience (pp. 293-294). Exponential increases in data flow, combined with the shift from traditional reporting to entertainment-style presentation, have produced a "new mediatized environment" for financial market activity (p. 291).

Although Clark et al. are primarily concerned with exposing media culpability for the speculation and "hype" that characterize financial markets in the new knowledge economy, their study also demonstrates the extent to which the growing numbers of global media consumers are increasingly offered "infotainment" rather than reliable information. In the realm of information exchange, the safety and efficiencies that generate trust and reliance upon those communications have been replaced with a tribal drumbeat of more emotionally charged, while less factually grounded, news. As Cappella and Jamieson $(1996,1997)$ have shown, the trend away from "issue-based" frameworks for political news stories and toward "strategic frames" that emphasize negative traits in public officials (such as self-interest and competitiveness) has not only contributed to public cynicism about government. In addition, "public distrust of political institutions and processes may have attached itself to the bearers of information about those institutions - the news media themselves" (Cappella and Jamieson 1996, p. 83). We have taught ourselves the very caution that leads to social disruption, thus lessening Arrow's vital "lubricant" or glue within our social systems.

The generalized distrust of news media has significant implications for corporate reputation. As ICT innovations have brought media platforms into more arenas of our daily life, and information flows increase, Scott and Walsham (2005) propose that one consequence is "that organizations are subject to an unprecedented level of transparency, which increases vulnerability to reputation risks" (p. 315). Another consequence of the growth of 
FIGURE 1 "Traditional" Stakeholder Map. Source: Adapted from Freeman (1984/2010).

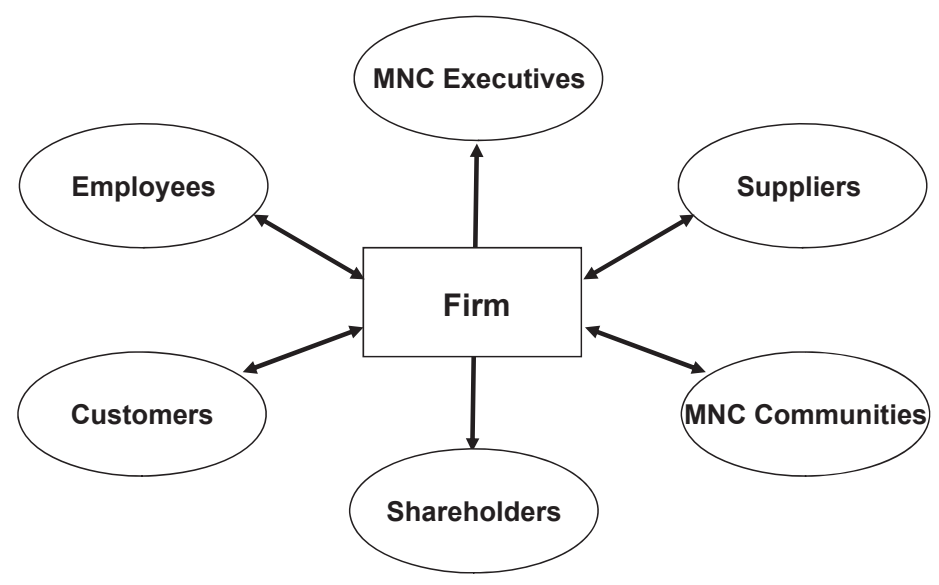

new information technologies is that "in a knowledge economy, people rapidly deconstruct empty, glossy public relations" (p. 319). Companies attempting to manage their reputations in this environment are subject to higher degrees of reputational vulnerability, yet at the same time, PR efforts that attempt to communicate with external stakeholders take place within a culture that is increasingly skeptical of information delivered by the media sources through which this communication takes place.

Finally, some of the loss of trust has to do with corporate centrism and firm-centric stakeholder models. Since the advent of stakeholder theory, companies have tended to draw stakeholder maps in order to align their interests with various stakeholders. This encourages companies and their managers to think carefully about all those groups who affect and who are affected by their company (see Figure 1). However, there is a downside to this process as well. Almost every corporate stakeholder map depicts the company in the center. In this traditional version, one's focus is drawn to the company first, as the "center," even when one carefully delineates various stakeholder relationships. In global settings in particular, this reaction is disarming because it encourages an illusion that the company is the sole, or at least 
the primary, locus of activity. But, in fact, companies are not in the center; they are embedded in a network of complex political, cultural, and economic relationships, many of which entail mutual trust. Neglecting these relationships or imagining the company is in a leadership-centrist, and thus hierarchically superior, position in regard to these relationships downgrades many of their activities into merely fiscal transactions. "This firm-centric depiction may prevent companies and their managers from viewing the firm from the perspectives of others: their primary and secondary stakeholders, or from the context within which they operate, which may be culturally, politically, or economically alien. This sort of thinking may also preclude firms and even their stakeholders from taking into account perspectives that will affect their operations, particularly in diverse cultures" (Bevan and Werhane forthcoming), and thus would devalue trust relationships in these communities.

\section{RESTORING TRUST IN COMMERCE}

Given these bleak scenarios, is there any hope of restoring trust and overcoming distrust in our companies and thus in markets, free enterprise, and commerce? Legalistic approaches to repairing trust may be effective in improving compliance, but formal rules are less effective-and may in fact be damaging - to the task of building trust (Flores and Solomon 1998; La Porte and Metlay 1996; Sitkin and Roth 1993). As Ghoshal et al. (1999) suggest, one can invigorate a company and embed trust and purpose in an organization by focusing on cooperation instead of compliance and by concentrating on values rather than rules. This reorientation toward cooperation and values would require not merely reframing a definition, but reframing the standard corporate culture that we see in today's business environment. Our call for this transformation builds upon La Porte and Metlay's (1996) assertion that when organizations face "a serious deficit of trust, adding even genuine and sincere trust-evoking actions to the standard repertoire of behaviors is not likely to be very effective" (p. 343). Edelman (2010) comes to a similar conclusion after surveying opinion leaders regarding trust in global business, asserting that to strengthen reputation, today's companies must 
build a "mosaic of trust" that engages all stakeholders (p. 7). In a climate characterized by the expectation of corporate opportunism and the perceived incongruence of corporate/public values, firms "need to develop entirely new behavioral recipes in which all the choices hang together and reinforce each other like threads in a fabric" (La Porte and Metlay 1996, p. 343). Developing a "behavioral recipe"-or "mosaic"-of mutually reinforcing strategies entails a commitment to prioritize trust in both the "internal operations" of the firm, and the "external relations" between the firm and communities affected by its activities (La Porte and Metlay 1996).

In this section, we recommend four cultural changes that firms might adopt as part of a holistic approach prioritizing trust relations within its internal operations and in its relations to external stakeholders: fostering collaborative leadership models, giving names and faces to the various stakeholder groups with whom a company has relationships, engaging in open and transparent dialogue with external stakeholders across multiple media platforms, and decentering the firm in stakeholder maps. When taken up as elements in a broad reorientation of corporate culture, we submit that these cultural changes have the potential to guide firms in their efforts to repair the trust deficit, and overcome the climate distrust, which has been exacerbated by the recent financial crisis.

One way to begin to restore trust is to redefine the concept of leadership. Rather than continue to reinforce the mind-set that leaders are "individuals who significantly influence the thoughts, behaviors, and/or feelings of others," it is useful to reformulate that idea by suggesting that "[l]eadership is interactive, . . an influence relationship among leaders and followers who intend real changes [reflecting] their mutual purposes" (Rost 1991, p. 102, quoted in Adler 1997, p. 171). Or, as Alfie Kohn (1992) has suggested, "the real alternative to being Number One is not being Number Two; it is dispensing with rankings altogether" (p. 102). Conceptualizing leadership as cooperative rather than hierarchical opens up opportunities for building trust within the firm's internal operations. Cook and Schilke (2010) argue that "[w]hile there is no simple way in which dyadic, relational trust transfers to larger units in which the dyad is embedded, it is one path by which trust can be rebuilt when distrust exists. . . . With distrust 
that has generalized, rebuilding trust at the relational level may be one of the only mechanisms for resolving the underlying trust breach" (p. 102). When firm leaders understand themselves to be working together in a cooperative relationship with employees and enact this role within the firm's internal operations, their efforts to develop a climate of shared value and purpose may offer a significant bulwark against distrust.

The former chief executive officer (CEO) of ShoreBank, Anne Arvia, now CEO of Nationwide Bank and listed in 2009 as one of the most powerful women in banking (Klein and Sausner 2009; Kohn 1992), models this form of leadership. She describes her leadership at ShoreBank:

I work very hard to know all 400 employees by name, and a little bit about them, and spend a lot of energy doing that. From a business standpoint, they know day-to-day what's going on. They know better than I do, in a lot of ways. I want them comfortable enough-Teller, Senior Manager, whatever-to pick up the phone. The mail guy walked in the other day and talked to me about a branch closing that had happened and the customer's perspective of it. And that's so wonderful that he felt comfortable enough. . . . So that's one thing I work very hard at, and I like to do that. I hope that that translates into respect and valuing of their opinion. I think that's the most important thing that I can do-consistent, fair, respectful treatment of everybody, whatever your title is. . . . I always tell people that if a Teller calls me, and the Chairman calls, I'd call the Teller back first. Because if a Teller's calling me, something's really wrong and it's likely it's systematic, and it's more related to something system-wide. The Chairman's call is obviously important, but it's probably more of a systematic issue [with the Teller]. ... There's just been a massive shift in the collaboration, expectations, and the way we've done the whole conversion of our reporting systems, of our management systems, of our accountability systems across the board. That was huge. And during that whole time we were posting record profits and record development... The ideal organization is one that empowers its people. If you do that you can do anything. Any strategy, anywhere you want to go if you have people who feel empowered, and are capable of course, I mean that's the driver. (Werhane et al. 2007, pp. 17-20) 
In addition to restoring the mutual perception of value congruence needed to reduce distrust, collaborative leadership helps to mitigate the blind trust that results from the more traditional hierarchical model discussed earlier and the resulting problem of followership obedience. When leaders such as Arvia give their employees responsible jobs and trust their skills, the obedience quotient goes down (Kohn 1992). Combining this cooperative leadership style with a "names and faces" approach reinforces that trust.

But what do we mean by a "names and faces" approach, and how is it possible, in a medium- or large-sized organization, to acknowledge everyone by name? Of course, deep familiarity with all employees-not to mention all affected stakeholders-is impossible in large firms, but we suggest a feasible alternative. As we noted earlier, there were approximately 14 million mortgages "under water" in the United States in 2009 (Cendrowski 2009). That is too many people to take into account. So let us consider just one family. According to a New York Times report, Edward and Maria Moller, two school teachers in New York State, bought a modest house in 2005 for $\$ 460,000$. It is now worth $\$ 312,000$, so they owe more on their mortgage than the house is worth. With the increases in their interest rates, even with an interest-only loan, their two salaries will not be sufficient to meet their payments by 2013 (Streitfeld 2009, p. B1; see also Figure 4). This simple naming story about one individual family brings home the dynamic of the subprime mortgage crisis even though one cannot literally come to know the 14 million sufferers or know all their individual stories. Using narrative in organizations to tell stories of individual stakeholders is one effective means to give names and faces to the challenges that have arisen based on the deterioration of trust and rise of distrust, and thus personalize the stakeholder relationships on which it is based.

This "names and faces" effort also reinvigorates trust by altering those relationships from ones merely of reciprocity or exchange to what Paul Ricoeur calls "recognition." Stakeholder theory introduced the idea that stakeholder relationships are relationships of reciprocity where each party-for example, the company and a particular set of stakeholders-affect and are affected by each other; thus, each has obligations to the others. For example, employee/employer relationships are or should be 
mutually reciprocal relationships where decent working conditions, fair treatment, and pay are exchanged by the employer for work contributions. These relationships, however, tend to be transactional. Thus, trust may devolve on either side if relations are thought of as mere exchanges. On the other hand, these relationships can be strengthened if there is, in addition, recognition of the other as an individual with human identity. That form or recognition goes beyond reciprocity because the obligations on either side of the exchange are not merely what is reciprocally due or expected. Rather, recognition entails the acknowledgment of the uniqueness of individual human agents acting within concrete historical contexts (Ricoeur 2005, ch. 3). Ideally such relationships should be mutual, such that the mutual recognition of the other party as a human agent, not merely a reciprocal stakeholder, helps to break up firm-center stakeholder mind-sets that are not conducive to trust. The "names and faces" or mutual recognition approach to stakeholder relations extends the distrust-reducing mechanism of dyadic, relational trust building to conceptualize the firm's external, as well as its internal, operations.

Managing corporate reputation through transparent and open lines of communication with stakeholders is a constitutive element of the attention to external operations for restoring trust under conditions of distrust (La Porte and Metlay 1996). Yet in the media-saturated environment that we described earlier, firm relations with external stakeholders must negotiate the challenges of communicating with publics that are distrustful of media and increasingly reliant upon information that flows from new ICT platforms that engender anxiety among many users. As Snider et al. (2003) point out, although the Internet "provides a variety of new content characteristics for corporations to use that enhance their communication effectiveness," it also "allows groups to view messages designed for other stakeholders that are not intended for them. . . . As a result, organizations no longer control the flow of information among concerned parties" (p. 176). Corporate efforts to use the tools of digital ICT media-such as corporate web sites, social media sites, and engagement with the new digital media outlets-to communicate with particular stakeholder groups must contend with the fact that these efforts can no longer be fully controlled by corporate PR strategies. External stakehold- 
ers may have access to information about companies that extends far beyond the messages that companies would prefer to communicate, and in addition, stakeholders may be wary of accepting corporate communications that are transmitted through the media at face value. However, rather than framing the vulnerability to reputational risk that companies face when their operating environment no longer assures them control over information flow as a problem, we suggest that firms see this environment as an opportunity to forge more egalitarian communication exchanges with external stakeholders.

As La Porte and Metlay (1996) have argued, a fundamental condition of trust relations is that "[p]arties have a reasonably equal part in defining the terms of their relationship" (p. 343). In light of high levels of public distrust of media and the flood of information enabled by new ICTs, corporate reputation cannot be approached via PR strategies that distribute selected information in a top-down approach, from upper levels of management to stakeholders. Certainly, these new pressures open corporate reputation to high levels of risk. With these new risks, however, come new opportunities to build relationships with those parties impacted by corporate practices. Miles et al. (2006) point to the benefits that new ICTs can provide to firms interested in developing stronger dialogic relations with stakeholders: ". . . the rapid and widespread adoption of e-mail and the Internet for intra and inter organizational communications made it possible for all stakeholders to have a voice in organizational issues. These changes altered the communication flow within organizationswhich traditionally flowed downward-to one which also allows stakeholders...to directly communicate with top executives" (p. 197).

While admittedly increasing the vulnerability of corporate reputation by undermining corporate control of information, new ICTs also enable a direct dialogue between top executives and external stakeholders that provides opportunities to build trusting relations that were unavailable in previous eras. The new vulnerabilities that corporate reputations are exposed to in today's information-driven society, Scott and Walsham (2005) argue, have generated "changing trust relationships, including the emergence of a new social contract between organizations and their stakeholders" (p. 319). This "new social contract" requires that organi- 
zations build and sustain open channels of communication to their diverse and differently situated stakeholder groups at the local, state, and global levels now interconnected by ICT products. Edelman (2010) adds an additional requirement, proposing that, as part of a "mosaic" of trust-building efforts, companies must attend to the fact that today's public needs to hear information multiple times, from multiple sources, to find it credible.

A trustworthy corporate reputation in today's media environment does not only require engagement with many different stakeholder groups, across many different communication platforms; it also requires that this engagement is persuasive and transparent. Miles et al. (2006) propose that businesses conceptualize open dialogue with external stakeholders as crucial "strategic conversations." Strategic conversations "are multi-directional multidimensional communication mechanisms for better shaping and integrating the strategic intent of top management with both the firm's capabilities and the competitive realities the organization encounters" (p. 196). Although such conversations have tended to be limited to dialogues between upper management and contact employees, Miles et al. (2006) argue that the communications that inform company strategy must include "open ended, bi-directional dialogue between management and other relevant stakeholders" (p. 197). Without substantive, open input from parties affected by firm policy, companies put themselves at high risk of enacting policies that undermine their reputations with stakeholders. New ICTs create opportunities to start and sustain strategic conversations with external stakeholders. Such strategic conversations, if they are to be successful, require that corporate culture shifts its focus from managing reputation through information control and toward building a reputation for trustworthiness by partnering with stakeholders to develop corporate strategies that acknowledge and incorporate the interests of both shareholders and impacted external parties.

Finally, firm-centered stakeholder maps encourage firms to develop egocentric thinking such that the primary unit of analysis is the firm despite the importance of other stakeholders in adding value to the company. When stakeholders are perceived to be less valued than the firm (even when they are not), this perception creates anxiety and loss of trust in the firmstakeholder relationships. Moreover, a firm-centered model belies 
FIGURE 2 Networked or Systems Stakeholder Map.

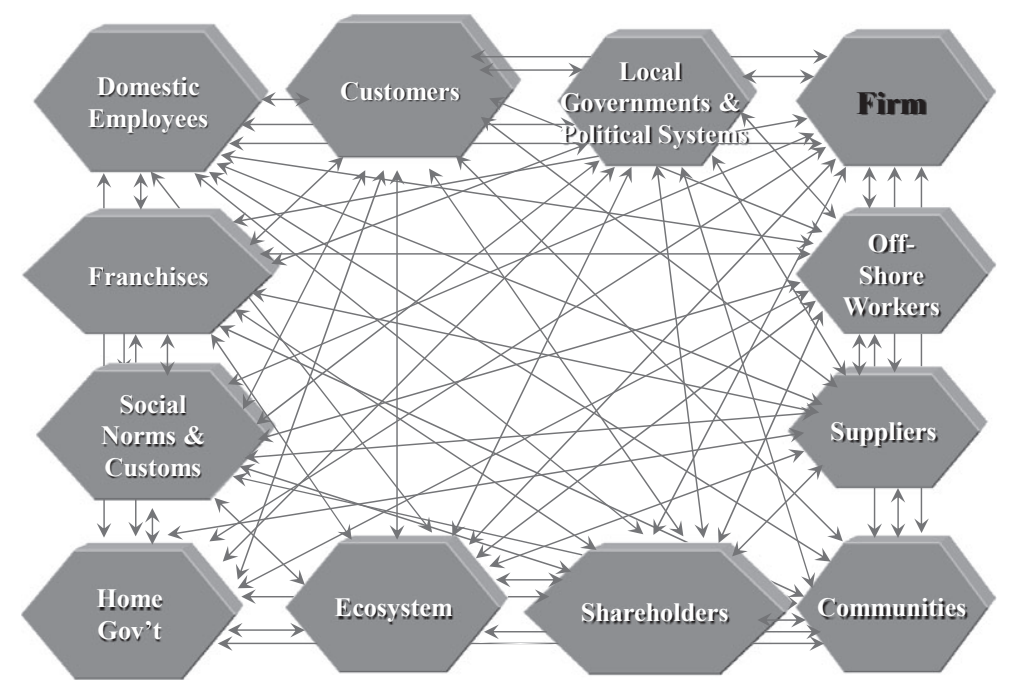

the experience of global companies in multicultural settings. As Edelman (2010) succinctly notes, the market environment today "is no longer a shareholder but a stakeholder world" (p. 7). Companies today are part of an internetworked set of systems in which they are just one of a variety of participants (Figure 2). There are a number of ways to deconstruct this firm-centered model that will garner more trust in the organization and in its stakeholder relationships. For example, Novo Nordisk puts patients with diabetes in the center of its corporate stakeholder model in order to remind employees of what the company is about, that is, curing disease (Figure 3). Another means to decenter the firm and refocus attention on interdependent relationships is to place an actual picture of a stakeholder in the center. For example, in focusing attention on the subprime mortgage crisis, one could place an actual family, Edward and Maria Moller, in the center (Figure 4). This refocusing combines the decentered model of firm/stakeholder relations with the "names and faces" approach, thereby accenting the realization that loans are made to real individual families, some of whom will be in deep financial trouble as a result. 


\section{FIGURE 3 Customer-centric Stakeholder Model at Novo Nordisk.}

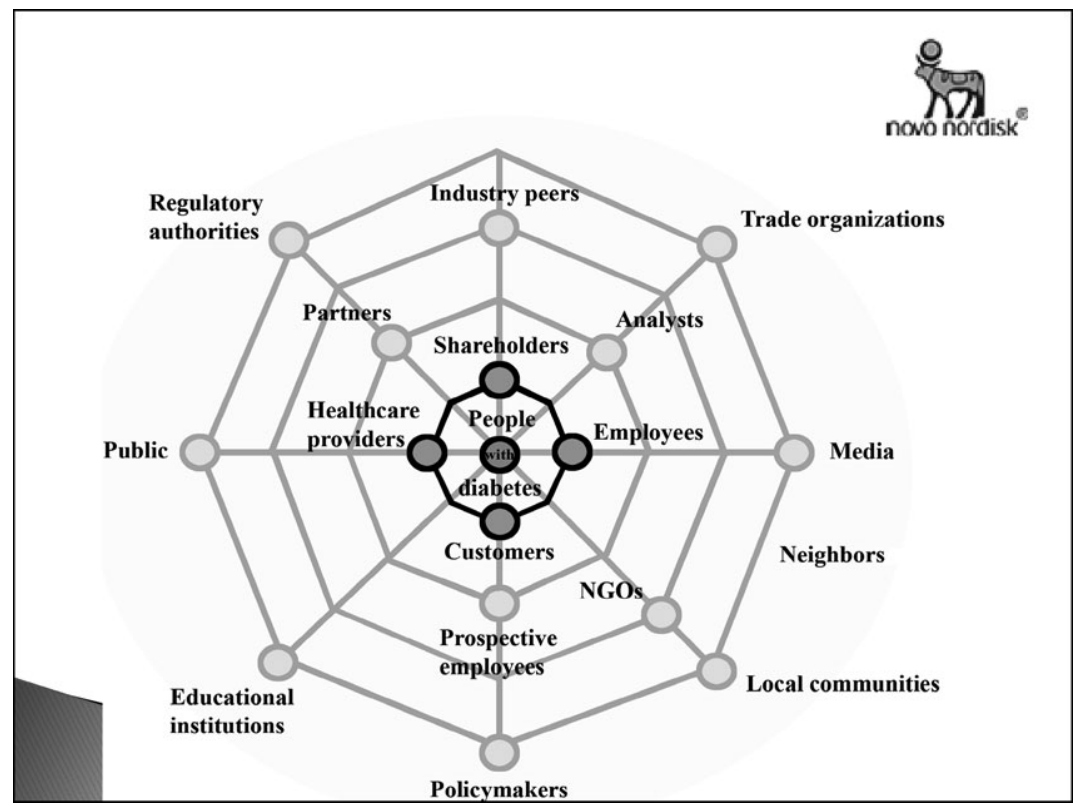

FIGURE 4 Alternative Stakeholder Map.

Source: Adapted from Freeman (1984/2010).




Global companies usually find themselves involved in a complex network of disparate stakeholders and stakeholder groups where they are not necessarily the center of attention.

But how does this reconfiguration create more trust between stakeholders? Let us consider two examples. When Royal Dutch Shell first began drilling for oil in the Ogoni territories in Nigeria, it failed to take seriously the local setting in which it was drilling and the cultural impact of its exploration in that community. Thus, Shell engendered dramatic distrust among the Ogoni, and its alliance with the Nigerian military did little to mitigate that issue. After the Nigerian government hanged a well-known Ogoni protestor and activist, Ken Saro-Wiwa, Shell began to rethink their drilling activities in Nigeria and to establish trust relationships among the Ogoni (Newberry and Gladwin 2002). As a "lesson learned," Exxon Mobil, in partnership with the World Bank, has tried to consider local concerns in its drilling operations in Chad and the construction of its pipeline through Pygmy and Bantu territories in Cameroon. By working with indigenous people as partners, employing nongovernmental organizations and social workers for that region, and engaging in public works projects, ExxonMobil and its partners have created a stronger climate of trust (Useem 2002). ${ }^{6}$ None of these situations is perfect, but ExxonMobil has shown that firms can create trust in foreign settings and add value as well.

\section{CONCLUSION}

We have examined several challenges to restoring trust in our political economies and proposed that these challenges might be overcome through transformations in corporation culture. To be sure, many of the corporate mind-sets that undermine trust relationships are deeply entrenched. We do not presume that it will be an easy task to overcome the preoccupation with quantification, valorization of hierarchical leadership and blind trust in employees, anonymous view of core stakeholders, reputational risks of new media formats, or firm-centric stakeholder models. It will be highly tempting for firms to remain willfully blind to the mind-sets that interfere with regaining and sustaining public trust, particularly if changes to corporate culture are perceived as posing risks 
to profitability. However, we maintain that this task is both feasible, as seen in the examples of ExxonMobil and Shell, and crucial. Why is creating a climate of trust within organizations and in communities where companies operate so important? There are obviously reasons of utility. It has taken Shell decades to recover trust in Nigeria, and its efforts are still ongoing, at a very high price tag. Moreover, if Tom Friedman is correct that the world is becoming "flat" such that "globalization has now shifted into warp drive" (Friedman 2005; Wright 2005), then moving into new markets requires that global companies must work to create conditions conducive to trust. Otherwise, they will find themselves without local partners and thus without new market share. The Enron mishandling of its Dabhol project in India is just one example of how the absence of trust can lead to loss of new markets (Rangan and McCaffrey 2004). A less corporate-centric perspective is part of developing such new trust relationships. Third, unless global companies reformulate their leadership models as collaborative rather than hierarchical, the "I just work here" middle manager philosophy will persist to the detriment of corporate behavior and thus trust in those institutions. There is also a danger that young women and men will not be attracted to these companies, and the loss of excellent talent will be the result.

Finally, corporations must acknowledge the changing media landscape and contribute to the re-establishment of trusted lines of communication with stakeholders. Trust in media can only be restored by providing well-conceived, properly sourced information to media consumers; today's words populate new forms of media in a world where very little is taken at face value. While words originally printed in ink must inevitably give way to their digital cousins, today's digital cynicism does not necessarily need to accompany this change. By using new ICTs to provide credible information to, and open up dialogic opportunities to learn from, diverse audiences of impacted stakeholders, corporations can strengthen their reputation for trustworthiness.

We will end with a narrative-a true story about trust. In New Delhi, as well as in other large cities in India, children, usually boys with poor or no education, flock to the city from small villages looking for work and excitement. There is little in the way of public services to help these boys; they are usually homeless and scrape by from meager earnings on the streets. However, 
some find night shelters where they are provided beds and basic sustenance. In 2000, the National Foundation for India began the Children's Development Bank (CDB). The CDB is bank owned and run by children under the oversight of an adult banker. The CDB trains children from the shelters in the rudiments of banking and helps to set up small kiosks in the shelters where the children run the bank. They collect earnings from the working children, set up banking accounts, and provide each child with his own bank book. Every evening, the children who have worked on the streets deposit money at the kiosk, managed by another child from the shelter, and that bank manager, in turn, deposits the money in the CDB. Interest is paid on the deposited money, and children can withdraw money from the bank in the shelter; when they are 18 years old they have to close this account. To date, over 1,300 children are served by the CDB bank in Delhi and almost 10,000 across India. The CDB has opened branches in Nepal, Bangladesh, and Afghanistan (Eliason 2009).

We conclude with this story because of the extraordinary trust that has developed in the shelters among the children and the child-bankers. If children between the ages of 8 and 18 can become bankers and be trusted with other people's money, without written contracts or draconian laws, there is no reason why such trust relationships cannot be reinvigorated in the developed world among bankers, mortgage brokers, hedge funds, other traders, and the stakeholders that are impacted by their practices. The CDB has set up the model. Surely, it can be replicated.

\section{NOTES}

1. Although identification of these two components of trust relations is nearly universal in the literature, scholars differ in the terms used to describe them. Despite occasional differences in terminology, definitions of competency trust are largely uniform. However, important differences have arisen in naming the component of trusting and distrusting relationships that is linked to values. For example, Sitkin and Roth (1993) refer to the need for "value congruence" to prevent the emergence of distrust, while Hardin describes a similar requirement of shared values as "benevolence trust." The value-related component has also has been 
termed "moralistic" trust (Uslaner 2010) or "goodwill" trust (Sengün and Wasti 2010), and Poppo and Schepker (2010) refine this component further by distinguishing between "benevolence" and "integrity" trust. We have avoided using the term "benevolence trust" because it implies that trust relationships are primarily based in benevolence or kindness. But that is not true. Trust relationships are based on beliefs by both parties that the relationship has shared values or goals and will be beneficial to each party. This kind of relationship entails the expectation of fair reciprocity, but it does not necessarily entail benevolence.

2. One of the questions that arises is why, in an open society such as evidenced in most Western nations, we do not see more in the way of cheating and deception, as it is so easy to do and so difficult to detect. The answer, we suggest, lies at least partly in the fact that we are afraid to threaten the "glue" of trust.

3. Bevan and Werhane (forthcoming) have described mental models or mind-sets as follows. "Mental models might be hypothetical constructs of the experience in question or scientific theories, they might be schema that frame the experience, through which individuals process information, conduct experiments, and formulate theories. Mental models function as selective mechanisms and filters for dealing with experience. In focusing, framing, organizing, and ordering what we experience, mental models bracket and leave out data, and emotional and motivational foci taint or color experience. Mental models, as Peter Senge carefully reminds us (Senge, 1990), function on the organizational and systemic levels as well as in individual cognition. Sometimes, then, how we depict accountability relationships within an organizational culture creates mental habits that may or may not be as appropriate in new settings. Similarly a political economy can be trapped in its vision of itself and the world in ways that preclude change on this more systemic level.

4. Milgram's original experiment involved three participants. The first participant assumed the role of "teacher" and was actually the subject of the experiment. The teacher was told that this was an experiment to determine the effect of punishment on learning. The second participant was identified as the "experimenter" and was usually played by a 31-year-old high school biology teacher wearing a gray technician's coat. Occasionally, this role was played by Milgram himself. The "learner" was a 47-year-old accountant with a kindly appearance, also a confederate of the experiment. Although it was made to appear to the teacher that the roles of teacher and learner were determined by drawing lots, in fact, the roles were predetermined. Milgram created a machine that 
appeared to be an electric shock generator, including switches representing shock levels that started at 15 volts and increased in 15-volt increments to 450 volts. As the learner was a confederate of the experimenter, the learner was never actually connected to the machine and was instead instructed how and when to respond and, in doing so, to pretend to receive actual shocks. The teachers were given a list of word pairs (e.g., "blue/girl") that were to be read aloud to the learners. Then each of the first words of the pair would be presented to the learner, followed by a set of words (e.g., "boy, girl, grass, tent"). The teacher was instructed to deliver a shock to the learner every time an incorrect answer was selected (e.g., grass) and then to repeat the correct paired word (in an effort to "teach"). Prior to reaching 150 volts, the learner would utter an occasional low grunt. However, at 150 volts the learner would insist, with a cry of pain, that he wanted the experiment to stop. If the teacher showed any resistance to continuing, the researcher would follow an experiment protocol and insist that the teacher had to continue. As the experiment progressed, the teacher would hear the learner desperately plead to be released or even complain about having a heart condition (again, based on Milgram's specific experiment protocol). Once the 300-volt level was reached, the learner would bang on the wall and demand to be released. Beyond this point, the learner would become completely silent for the remaining questions (Milgram 1969; Werhane et al. 2011).

5. Freeman and McVea address this problem in their 2005 essay "A Names and Faces Approach to Stakeholder Management," but they have not developed this very rich idea extensively.

6. Unfortunately, ExxonMobil and its other partner, the World Bank, have had to deal with Idriss Deby, the president of Chad and a genuinely untrustworthy individual who simply cannot keep his promises.

\section{REFERENCES}

Adler, N. 1997. "Global leadership: Women leaders," Management International Review 37: 171-196.

Arrow, K. 1974. The Limits of Organization. New York: Norton.

Barber, B. 1983. The Logic and Limits of Trust. New Brunswick, NJ: Rutgers University Press.

Barroso, J. M. 2009. "Joint Press conference with Prime Minister Reinfeldt before the G20 Summit Pittsburgh," September 24, http://www.europa-eu-un.org/articles/fr/article_9024_fr.htm, accessed December 27, 2010. 
Bauman, Z. 1993. Postmodern Ethics. Oxford: Blackwell.

Bevan, D., and Werhane, P. H. Forthcoming. "Stakeholder theory," in M. Painter-Morland, and R. ten Bos, eds., Business Ethics and Continental Philosophy. Cambridge: Cambridge University Press.

Bird, F., and Waters, J. 1989. "The moral muteness of managers," California Management Review 32: 73-88.

Blair, T. 2007. "Full text of Tony Blair's speech on the changing relationship between politics and the media, delivered on June 12," June 12, http://www.telegraph.co.uk/news/uknews/1554286/Full-text-ofBlairs-speech-on-politics-and-media.html, accessed December 28, 2010.

Bollier, D., Weiss, S., and Hanson, K. O. 1991. Merck and Co. Harvard University Graduate School of Business Administration Case \# 9-991021. Boston: Harvard Business School Press.

Brenkert, G. 1998. "Trust, morality, and international business," Business Ethics Quarterly 8: 293-318.

Cappella, J. N., and Jamieson, K. H. 1996. "News frames, political cynicism, and media cynicism," The Annals of the American Academy of Political and Social Science 546: 71-84.

Cappella, J. N., and Jamieson, K. H. 1997. Spiral of Cynicism: The Press and the Public Good. New York: Oxford University Press.

Catalyst. 2010. "Women on boards," http://www.catalyst.org/ publication/433/women-on-boards, accessed December 29, 2010.

Cendrowski, S. 2009. "As homeowners head 'underwater' another housing crisis looms," Fortune, August 12, http://money.cnn.com/ 2009/08/12/real_estate/housing_mortgages_underwater.fortune/, accessed December 28, 2010.

Cho, J. 2006. "The mechanism of trust and distrust formation and their relational outcomes," Journal of Retailing 82(1): 25-35.

Clark, G. L., Thrift, N., and Tickell, A. 2004. "Performing finance: The industry, the media and its image," Review of International Political Economy 11(2): 289-310.

Cook, K. S., and Schilke, O. 2010. "The role of public, relational and organizational trust in economic affairs," Corporate Reputation Review 13(2): 98-109.

Dullforce, A.-B. 2010. "FT global 500 2010," Financial Times, May 28, http://www.ft.com/cms/s/0/aelbe116-68cc-11df-96f100144feab49a.html, accessed December 28, 2010.

Earle, T. C. 2009. "Trust, confidence and the global financial crisis," Risk Analysis 29(6): 785-792.

Edelman, R. 2010. "Trust: 2010 Edelman trust barometer executive summary," http://www.edelman.com/trust/2010/, accessed December 28, 2010.

Eliason, E. 2009. "Children's development bank: Transforming street children into entrepreneurs," Social Earth, April 2, http:// www.socialearth.org/children's-development-bank-transforming-streetchildren-into-entrepreneurs, accessed October 1, 2011. 
Flores, F., and Solomon, R. C. 1998. "Creating trust," Business Ethics Quarterly 8(2): 205-232.

Freeman, R. E. 1984/2010. Strategic Management. Cambridge: Cambridge University Press.

Friedman, M. 1970. "The social responsibility of business is to increase its profits," New York Times Magazine, September 13: 32-33, 122, 126.

Friedman, T. 2005. The World Is Flat. New York: Farrar, Strauss and Giroux.

Fukuyama, F. 1995. Trust: The Social Virtues and the Creation of Prosperity. New York: Free Press.

Gambetta, D. 1998. "Can we trust 'trust?' ” in D. Gambetta, ed., Trust Making and Breaking in Cooperative Relations. Oxford: Basil Blackwell, pp. 213-238.

Gardner, H., and Laskin, E. 1995. Leading Minds. New York: Basic Books.

Ghoshal, S., Bartlett, C., and Moran, P. 1999. "A new manifesto for management," Sloan Management Review 40: 9-20.

Guillén, M. F., and Suárez, S. L. 2005. "Explaining the global digital divide: Economic, political and sociological drivers of cross-national internet use," Social Forces 84(2): 681-708.

Hardin, R. 2002. Trust and Trustworthiness. New York: Russell Sage Foundation.

Hobbes, T. 1651/1996. Leviathan. Oxford: Oxford University Press.

Karavidas, M., Lim, N. K., and Katsikas, S. L. 2005. "The effects of computers on older adult users," Computers in Human Behavior 21(5): 697-711.

Klein, A., and Sausner, R. 2009. "Taking charge in turbulent times: The 25 most powerful women in banking in 2009," U.S. Banker, http:// www.americanbanker.com/magazine/119_10/taking_charge_in_ turbulent_times-1002115-1.html, accessed October 1, 2011.

Kohn, A. 1992. No Contest. New York: Houghton Mifflin.

Kramer, R. 1999. "Trust and distrust in organizations: Emerging perspectives, enduring questions," Annual Review of Psychology 50(1): 569-598.

La Porte, T. R., and Metlay, D. S. 1996. "Hazards and institutional trustworthiness: Facing a deficit of trust," Public Administration Review 56(4): 341-347.

Lewicki, R. J., McAllister, D. J., and Bies, R. 1998. "Trust and distrust: New relationships and realities." Academy of Management Review 23(3): 438-458.

Lewis, M. 2009. "The man who crashed the world," Vanity Fair, August.

Luhmann, N. 1979. Trust and Power. Chichester, UK: Wiley.

Matanda, M., Jenvey, V. B., and Phillips, J. G. 2004. "Internet use in adulthood: Loneliness, computer anxiety and education," Behaviour Change 21(2): 103-114.

McVea, J., and Freeman, R. E. 2005. "A names-and-faces approach to stakeholder management," Journal of Management Inquiry 14: 57-69. 
Merck Pharmaceuticals. 2010. "Looking ahead: 2009-2010 corporate responsibility review," www.merck.com/corporate-responsibility/docs/ MRK_CSR09_Mech_33_101116.pdf, accessed October 1, 2011.

Miles, M. P., Munilla, L. S., and Darroch, J. 2006. "The role of strategic conversations with stakeholders in the formation of corporate social responsibility strategy," Journal of Business Ethics 69(2): 195205.

Milgram, S. 1963. "Behavioral study of obedience," Journal of Abnormal and Social Psychology 67: 371-378.

Milgram, S. 1969. Obedience to Authority. New York: Harper and Row.

Mossberger, K., Tolbert, C. J., and Stansbury, M. 2003. Virtual Inequality: Beyond the Digital Divide. Washington, DC: Georgetown University Press.

Newberry, W., and Gladwin, T. N. 2002. "Shell and Nigerian oil," in T. Donaldon, P. H. Werhane, and M. Cording, eds., Ethical Issues in Business, 7th ed. Upper Saddle River, NJ: Prentice-Hall Pearson, pp. 522-541.

Ornstein, N. J., Mann, T., and Malbin, M. J. 2008. Vital Statistics on Congress. Washington, DC: Brookings Institute Press.

Pew Research Center. 2010. "The people and their government: Distrust, discontent, anger and partisan rancor," April 18, http://peoplepress.org/report/606/trust-in-government, accessed December 28, 2010.

Poppo, L., and Schepker, D. 2010. "Repairing public trust in organizations," Corporate Reputation Review 13(2): 124-141.

Rangan, V. K., and McCaffrey, A. 2004. Stakeholder Analysis: Enron and the Dabhol Power Project in India (Case \#504-062). Cambridge, MA: Harvard Business School Publishing.

Ricoeur, P. 2005. The Course of Recognition. Translated by D. Pellauer. Cambridge, MA: Harvard University Press.

Rosenberg, H., and Feldman, C. S. 2008. No Time to Think: The Menace of Media Speed and the 24-Hour News Cycle. New York: Continuum.

Rosener, J. 1990. "Ways women lead," Harvard Business Review 68: $119-125$.

Rost, J. C. 1991. Leadership for the Twenty-first Century. New York: Praeger.

Scott, S. V., and Walsham, G. 2005. "Reconceptualizing and managing reputation risk in the knowledge economy: Toward reputable action," Organization Science 16(3): 308-322.

Senge, P. 1990. The Fifth Discipline. New York: Doubleday.

Sengün, A. E., and Wasti, S. N. 2010. "Trust types, distrust, and performance outcomes in small business relationships: The pharmacydrug warehouse case," The Service Industries Journal 31: 287-309. doi: $10.1080 / 02642060902759137$

Silver-Greenberg, J. 2010. "Dead soul is a debt collector," The Wall Street Journal, December 31: A1. 
Sitkin, S. B., and Roth, N. L. 1993. "Explaining the limited effectiveness of legalistic remedies for trust/distrust," Organization Science 4(3): 367-392.

Slovic, P. 1993. "Perceived risk, trust and democracy," Risk Analysis 13: 675-682.

Smith, A. 1762/1976. A Theory of Moral Sentiments. New York: Oxford University Press.

Snider, J., Hill, R. P., and Martin, D. 2003. "Corporate social responsibility in the $21^{\text {st }}$ century," Journal of Business Ethics 48(2): 175-187.

Streitfeld, D. 2009. "As an exotic mortgage resets, payments rocket," New York Times, September 9: B1.

Suri, R., Lee, J. A., Manchanda, R. V., and Monroe, K. B. 2003. "The effect of computer anxiety on price value trade-off in the on-line environment," Psychology \& Marketing 20(6): 515-536.

Useem, J. 2002. "Exxon's African Adventure," Fortune, April 15: 102-114.

Uslaner, E. W. 2010. "Trust and the global financial crisis of 2008," Corporate Reputation Review 13(2): 110-123.

Werhane, P. 2011. "Globalization, mental models, and decentering stakeholder approaches,” in R. Phillips, ed., Stakeholder Theory: Impact and Prospects. Cheltenham, UK and Northampton, MA: Edward Elgar Publishers, pp. 111-129.

Werhane, P., Hartman, L., Moberg, D., Englehardt, E., Pritchard, M., and Parmar, B. 2011. "Social constructivism, mental models, and problems of obedience," Journal of Business Ethics 100: 103-118.

Werhane, P. H., Posig, M., Gundry, L., Ofstein, L., and Powell, E. 2007. Women in Business. New York: Praeger.

Wilfong, J. D. 2006. "Computer anxiety and anger: The impact of computer use, computer experience, and self-efficacy beliefs," Computers in Human Behavior 22(6): 1001-1011.

Wright, R. 2005. "The incredible shrinking planet. What liberals can learn from Thomas Friedman's new book," Review of the book The World Is Flat by Thomas Friedman. Slate, http://www.slate.com/id/2116899, accessed December 28, 2010.

Young, S. B. 2010. "Organizational and ethical behaviors: Anxiety has a hundred faces," Caux Round Table, April 30, http://www. cauxroundtable.org/newsmaster.cfm?\&menuid=99\&action=view \& retrieveid=63, accessed December 28, 2010. 